\title{
Cerebral Ischemic Lesions Detected With Diffusion-Weighted Magnetic Resonance Imaging After Carotid Artery Stenting: Comparison of Several Anti-embolic Protection Devices
}

\author{
Mahmoud M. TAHA, Masayuki MAEDA*, Hiroshi SAKAIDA, Kenji KAWAGUCHI, \\ Naoki TOMA, Akitaka YAMAMOTO, Tomofumi HIROSE, Youichi MIURA, \\ Masashi FUjImOTO, Satoshi MATSUSHIMA, and Waro TAKI
}

Departments of Neurosurgery and ${ }^{*}$ Neuroradiology, Mie University School of Medicine, Tsu, Mie

\begin{abstract}
Distal embolism is an important periprocedural technical complication with carotid angioplasty and carotid artery stenting (CAS). We evaluated the safety and efficacy of protection devices used during CAS by detecting new cerebral ischemic lesions using diffusion-weighted magnetic resonance imaging in 95 patients who underwent 98 CAS procedures: 34 using single PercuSurge GuardWire, 31 using double balloon protection, 15 using proximal flow reverse protection devices, 14 using Naviballoon, and 4 using filter anti-embolic devices. Diffusion-weighted imaging was performed preoperatively and postoperatively to evaluate the presence of any new embolic cerebral lesions. Postoperative diffusionweighted imaging revealed 117 new ischemic lesions. Three patients had new ischemic stroke, two minor and one major, all ipsilateral to the treated carotid artery. The remaining patients had clinically silent ischemia. The incidence of new embolic lesions was lower using the proximal flow reverse protection device than with the double balloon protection (33\% vs. $48.4 \%)$, but the volume of ipsilateral new ischemic lesions per patient was $136.6 \mathrm{~mm}^{3} \mathrm{vs.} 86.9 \mathrm{~mm}^{3}$, respectively. Neuroprotection with Naviballoon yielded ipsilateral lesions of large volume $\left(86.6 \mathrm{~mm}^{3}\right)$ and higher number (5.7 lesions per patient) than using the filter anti-embolic device $\left(34.8 \mathrm{~mm}^{3}\right.$ and 1 lesion per patient). New cerebral ischemic lesions after neuroprotected CAS are usually silent. The lower incidence of distal ischemia using proximal flow reverse and double balloon protection devices is limited by the larger volume and higher number of ischemic lesions.
\end{abstract}

Key words: carotid artery stenting, diffusion-weighted magnetic resonance imaging, neuroprotection, distal ischemia

\section{Introduction}

The recent revolution in endovascular intervention has added a feasible alternative to conventional surgical repair for the management of different neurovascular pathologies. Percutaneous carotid angioplasty and carotid artery stenting (CAS) has the potential of being minimally invasive, less traumatic, and safer in patients with a high surgical risk, resulting in shorter hospital stays. ${ }^{33)}$ However, CAS does carry inherent risks of morbidity and mortality. The main limitation of this technique is the risk of distal cerebral embolization caused by mobilization and migration of plaque fragments. ${ }^{8,32}$ Although

Received July 15, 2008; Accepted March 4, 2009 cerebral protection devices have been developed and are widely used to prevent periprocedural cerebral embolization, their application may result in additional complications..$^{9,20}$ Cerebral ischemia can be significantly reduced by using protected CAS compared to unprotected procedures, ${ }^{8,35)}$ whereas favorable outcomes have been reported with unprotected CAS and most of the neurological complications could not have been prevented with protection devices. ${ }^{25)}$ Cerebral protection can be achieved by different devices including filter embolic protection devices, distal balloon occlusion devices, and proximal flow reverse protection devices. Their efficacy has been evaluated in various in vitro ${ }^{19-22)}$ and clinical studies. ${ }^{11,12,34)}$ However, the number of new ischemic lesions and their volumes, as depicted by 
diffusion-weighted magnetic resonance (MR) imaging, are rarely studied as comparative criteria between neuroprotection devices.

The present study evaluated the safety and efficacy of different neuroprotection devices used during CAS in regard to the incidence, volumes, and numbers of the new cerebral ischemic lesions using diffusion-weighted imaging.

\section{Methods}

A total of 122 patients underwent 128 protected CAS procedures for treatment of occlusive carotid artery diseases at our institution between January 2001 and December 2005. Of these, 27 patients with incomplete data, who were lost to follow up or who were evaluated with a different MR imaging technique (5 $\mathrm{mm}$ slice thickness and $1 \mathrm{~mm}$ inter-slice gap) were excluded. The remaining 95 patients who underwent 98 CAS procedures were included in this study. All patients underwent complete neurological examination before, during, immediately after, and at 30 days, 3 months, and 6 months to 1 year after the intervention by a vascular neurosurgeon who was not involved in the CAS (S.M.).

All patients received $100 \mathrm{mg}$ of acetylsalicylic acid and $200 \mathrm{mg}$ of ticlopidine or $200 \mathrm{mg}$ cilostazol for at least 7 days before the procedure. All patients received 4000 to 5000 units of heparin intra-venously early in the procedure with an additional 1000 units/hour to maintain activated clotting times between 250 and 300 seconds, and $0.5 \mathrm{mg}$ of atropine sulfate to reduce bradycardia and hypotension induced by baroreceptor stimulation during CAS. After the procedure, patients were given $200 \mathrm{mg}$ of clopidogrel for 3 months and $100 \mathrm{mg}$ of acetylsalicylic acid indefinitely. Procedures were performed under general anesthesia until 2004, after which local anesthesia was used.

The transfemoral approach is the standard for percutaneous stenting, but the transbrachial approach was used in 2 patients, and direct carotid puncture was employed in 4 patients due to severe atherosclerosis or tortuosity of the blood vessels. The selection of the protection devices depended on the degree of stenosis, angioanatomy of the treated carotid artery, condition of the collateral circulation, presence of contralateral carotid artery stenosis, as well as the presence of anastomotic channels between the vertebrobasilar and carotid artery systems. Fifteen patients were treated using the Parodi Anti-embolic System (ArteriA Medical Science, San Francisco, Calif., U.S.A.), 34 patients were treated using the PercuSurge GuardWire (Medtronic AVF, Santa Rosa, Calif., U.S.A.), 31 patients were treated by simultaneous temporary occlusion of the internal carotid and external carotid arteries using the PercuSurge GuardWire and Sentry Balloon catheter (Boston Scientific, Tokyo), 14 patients were treated using the Naviballoon (Kaneka Medics, Tokyo), and 4 patients were treated with the use of a commercially available filter Mint Catch (Century Medical, Tokyo). The following stents were employed, Smart stent (Cordis, Johnson \& Johnson Co., Warren, N.J., U.S.A.) in 59 patients, Precise (Cordis, Johnson \& Johnson Co.) in 17 patients, Protégé (ev3 Inc., Plymouth, Minn., U.S.A.) in 9 patients, Wallstent (Target Therapeutic, Boston Scientific) in 6 patients, Acculink (Guidant Corporation, Indianapolis, Ind., U.S.A.) in 5 patients, Palmaz (Cordis, Johnson \& Johnson Co.) in one patient, and Aurora (Medtronic AVF) in one patient. Details of the previously reported procedures ${ }^{2,11,35)}$ were explained to the patients and informed consent was obtained.

MR imaging was performed before and after the procedures within 4 days using a $1.5 \mathrm{~T}$ MR imaging scanner (Signa Horizon Echospeed; GE, Milwaukee, Wis., U.S.A.). MR imaging sequences included fast fluid-attenuated inversion recovery (FLAIR) and diffusion-weighted imaging. The FLAIR sequence was performed with the following parameters: repetition time (TR)/echo time (TE)/excitation 8000 $\mathrm{msec} / 130 \mathrm{msec} / 1$, inversion time $2000 \mathrm{msec}$, matrix $288 \times 192$, field of view (FOV) $220 \times 220 \mathrm{~mm}$, and section thickness $5 \mathrm{~mm}$ with intersection gap $1 \mathrm{~mm}$. Total acquisition time was 3 minutes 28 seconds. Diffusion-weighted imaging was performed using a spin-echo echo-planar sequence with the following parameters: b values $1000 \mathrm{sec} / \mathrm{mm}^{2}$, TR/TE/excitation $5300 \mathrm{msec} / 65 \mathrm{msec} / 1$, matrix $128 \times 160$, FOV $240 \times 240 \mathrm{~mm}$, section thickness $3 \mathrm{~mm}$ with no gap, and 20 slices. Total acquisition time was 1 minute 20 seconds.

The trace diffusion-weighted images (b values $1000 \mathrm{sec} / \mathrm{mm}^{2}$ ) were evaluated for the presence or absence of new embolic lesions. Baseline lesion volumes were determined on an offline computer station. Diffusion-weighted imaging parameters were measured by placing regions of interest within the lesion on the trace images. The global lesion volume was determined by multiplying the area of diffusion hyperintensity by the sum of the slice thickness $(3 \mathrm{~mm})$. Imaging analysis was done by a neuroradiologist (M.M.) who was unaware of the clinical status of the patients or the protection devices used. The number, volume, location, and vascular territories of signal intensity abnormalities were detected by comparison to the preoperative diffusion-weighted images.

The location of the lesions was classified as the 
cortical and subcortical parts of the cerebrum, and the deep area defined as the basal ganglia and thalamus. ${ }^{13)}$ Minor stroke was defined as the loss of neurological function caused by an ischemic event which disappeared within 30 days of onset. Major stroke was defined as symptoms which persisted for more than 30 days following onset. The duration of clinical follow up ranged between 6 to 53 months (mean 29.4 months).

Data was analyzed using STATISTICA software ('99 edition by StatSoft, Inc., Tulsa, Okla., U.S.A.). Results were analyzed using the Fisher exact test, Student's t-test, Mann-Whitney rank sum test, or Duncan's multiple range test where appropriate to determine the efficacy and maximum neuroprotection offered by the anti-embolic devices, and compared using the $\chi^{2}$ method. A p-value $<0.05$ was considered to be statistically significant.

\section{Results}

Table 1 shows the demographic and clinical characteristics of the patients. Patients with new ischemic lesions on postoperative diffusion-weighted imaging showed several different characteristics from those without new ischemic lesions, including a higher incidence of symptomatic carotid artery stenosis $(\mathrm{p}<$ 0.05), more severe carotid artery stenosis ( $p<$ 0.001 ), and a higher incidence of contralateral carotid artery occlusion $(\mathrm{p}<0.001)$. The morphological variables of carotid plaque (ulceration, calcification, concentric, or eccentric) were not associated with a significantly higher incidence of distal ischemia. Hypertension, diabetes mellitus, and hyperlipidemia were the most commonly encountered risk factors, and medical risk factors were significantly associated with higher incidence of ischemic lesions $(\mathrm{p}<0.001)$.

Table 2 shows the characteristics of the new ischemic lesions. We found 117 new distal ischemic lesions in 42 patients (mean $2.8 \pm 2.05$ per patient). The incidence of new ischemic lesions was lower using distal balloon protection with the Naviballoon, Mint Catch filter device, and proximal flow reverse protection device (Parodi Anti-embolic System), compared to double balloon protection (PercuSurge

Table 1 Baseline demographic characteristics of the patients

\begin{tabular}{|c|c|c|c|c|}
\hline Characteristics & All patients & $\begin{array}{l}\text { Patients with new } \\
\text { ischemic lesions }\end{array}$ & $\begin{array}{l}\text { Patients without } \\
\text { new lesions }\end{array}$ & $\mathrm{P}$ \\
\hline No. & $98(100 \%)$ & $42(42.8 \%)$ & $56(57.2 \%)$ & $<0.01$ \\
\hline \multicolumn{5}{|l|}{ Sex } \\
\hline male & 89 (90.8\%) & $39(92.8 \%)$ & $50(89.3 \%)$ & $>0.05$ \\
\hline female & $9(9.2 \%)$ & $3(7.2 \%)$ & $6(10.7 \%)$ & $<0.01$ \\
\hline Age, years & $70.5 \pm 10.7$ & $72.5 \pm 8.4$ & $69.1 \pm 13.2$ & NS \\
\hline Symptomatic & $51(52 \%)$ & $24(57.1 \%)$ & $27(48.2 \%)$ & $<0.05$ \\
\hline Major stroke & 12 (12.2\%) & $8(19 \%)$ & $4(7.1 \%)$ & $>0.05$ \\
\hline Minor stroke & 19 (19.4\%) & $9(21.4 \%)$ & $10(17.8 \%)$ & NS \\
\hline TIA & $20(20.4 \%)$ & $7(16.6 \%)$ & $13(23.2 \%)$ & $<0.05$ \\
\hline Asymptomatic & $47(48 \%)$ & $18(42.9 \%)$ & $29(51.8 \%)$ & $<0.05$ \\
\hline \multicolumn{5}{|l|}{ Lesion severity } \\
\hline$<70 \%$ & 18 (18.4\%) & $5(11.9 \%)$ & $13(23.2 \%)$ & $<0.001$ \\
\hline $70-89 \%$ & 39 (39.8\%) & $19(45.2 \%)$ & $20(35.7 \%)$ & $<0.05$ \\
\hline$\geq 90 \%$ & 41 (41.8\%) & $18(42.9 \%)$ & $23(41.1 \%)$ & NS \\
\hline \multicolumn{5}{|l|}{ Morphology } \\
\hline Ulceration & 43 (43.9\%) & $20(47.6 \%)$ & $23(41 \%)$ & NS \\
\hline Calcification & 19 (19.4\%) & $8(19 \%)$ & $11(19.6 \%)$ & NS \\
\hline Concentric & $61(62.2 \%)$ & $25(59.5 \%)$ & $36(64.3 \%)$ & NS \\
\hline Eccentric & 37 (37.8\%) & $17(40.5 \%)$ & $20(35.7 \%)$ & NS \\
\hline Contralateral carotid artery occlusion & $18(18.4 \%)$ & $11(26.2 \%)$ & $7(12.5 \%)$ & $<0.001$ \\
\hline \multicolumn{5}{|l|}{ Risk factors } \\
\hline Hypertension & $35(35.7 \%)$ & $12(28.6 \%)$ & $13(23.6 \%)$ & $<0.05$ \\
\hline Diabetes mellitus & $29(29.6 \%)$ & $12(28.6 \%)$ & $17(30.4 \%)$ & $>0.05$ \\
\hline Hyperlipidemia & $17(17.3 \%)$ & $8(19 \%)$ & $9(16.1 \%)$ & NS \\
\hline Cardiac diseases & $9(9.2 \%)$ & $5(11.9 \%)$ & $4(7.1 \%)$ & $<0.05$ \\
\hline Others & $15(15.3 \%)$ & $4(9.5 \%)$ & $11(19.6 \%)$ & $<0.01$ \\
\hline No risk factor & $39(39.8 \%)$ & $10(23.8 \%)$ & $29(51.8 \%)$ & $<0.001$ \\
\hline
\end{tabular}

NS: not significant, TIA: transient ischemic attack. 
Table 2 Protective methods and characteristic features of new cerebral ischemic lesions

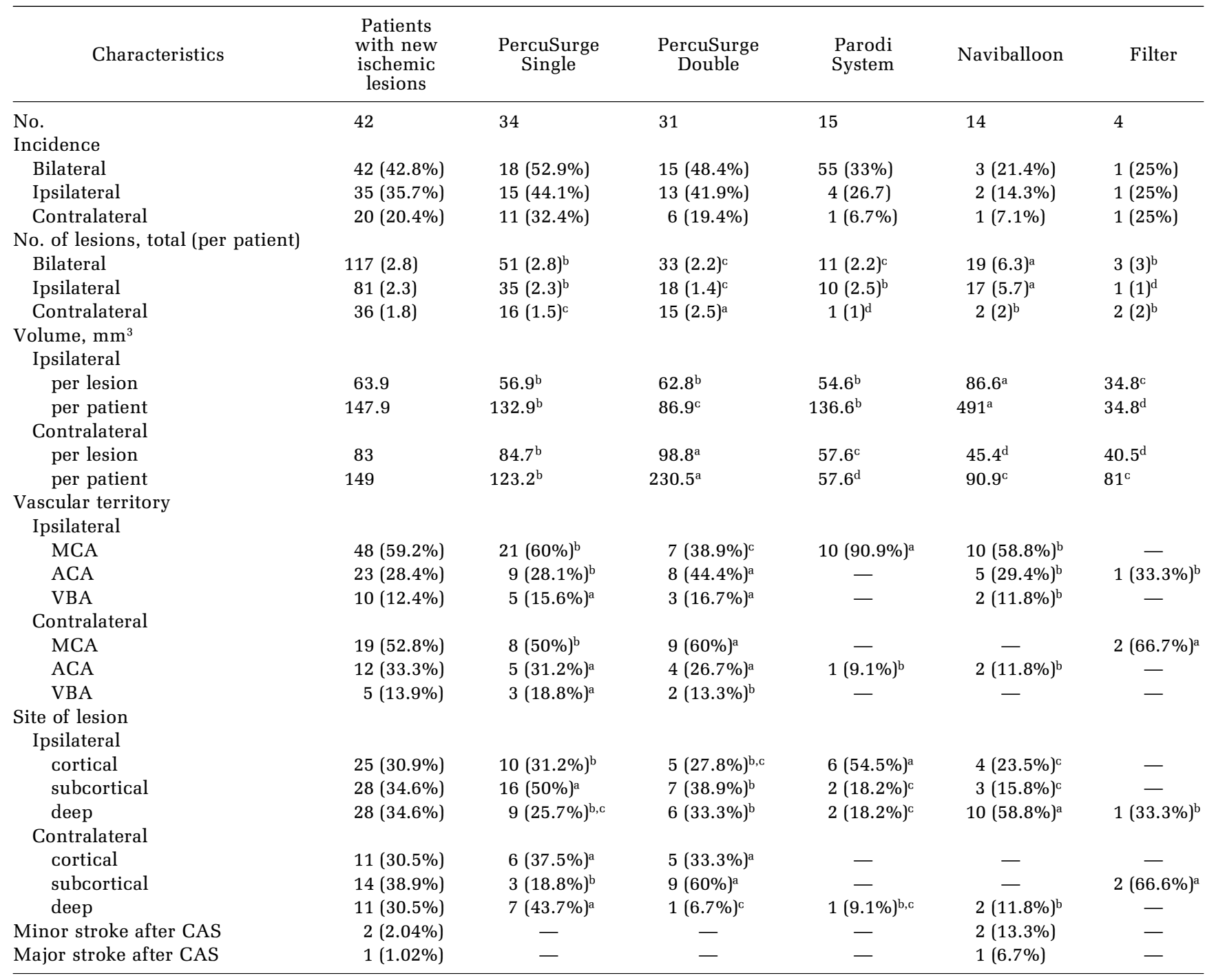

Superscript letters ${ }^{\mathrm{a}, \mathrm{b}, \mathrm{c}, \mathrm{d}}$ indicate comparison using Duncan's multiple range test in a descending manner. Numbers with the same letters show no significant difference, whereas numbers with different letters have statistically significant differences. ACA: anterior cerebral artery, CAS: carotid artery stenting, MCA: middle cerebral artery, VBA: vertebrobasilar arteries.

GuardWire with Sentry balloon catheter) and the single PercuSurge GuardWire. However, this lower incidence was not always associated with maximal neuroprotection in patients with new lesions as shown in Fig. 1. The volume of ipsilateral new ischemic lesions per patient using the proximal flow reverse device $\left(136.6 \mathrm{~mm}^{3}\right)$ was larger than that using double distal balloon protection $\left(86.9 \mathrm{~cm}^{3}\right)$, despite the lower reported incidence. Larger ipsilateral volume was also obvious using the Naviballoon $\left(491 \mathrm{~mm}^{3}\right)$. Distal balloon protection with the Naviballoon yielded more lesions (5.7 per patient) with larger lesion volume $\left(86.6 \mathrm{~mm}^{3}\right.$ per lesion). Three patients suffered neurological worsening fol-
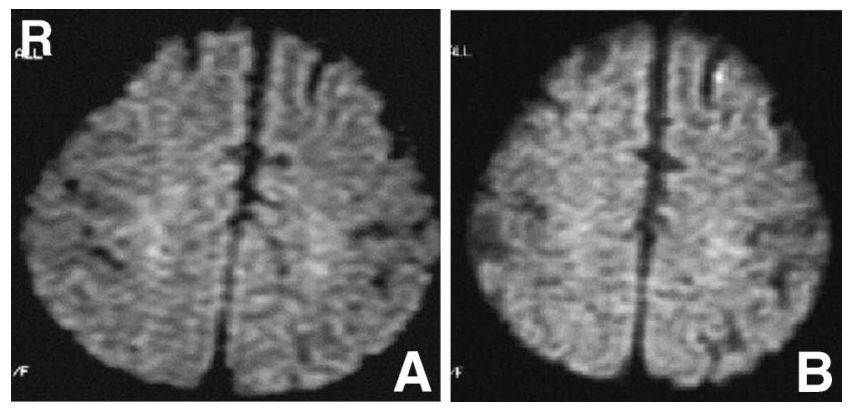

Fig. 1 Diffusion-weighted magnetic resonance images before (A) and after the procedure (B) showing new distal ischemic lesions ipsilateral to the treated carotid artery. 
lowing CAS with ipsilateral lesions, all were treated using the Naviballoon. Those patients had larger volumes and higher numbers of ischemic lesions.

\section{Discussion}

Noninvasive monitoring tools are preferred to investigate the safety and efficacy of carotid endarterectomy. ${ }^{15)}$ Diffusion-weighted imaging has proved to be superior to other MR imaging sequences and is now considered to be the best technique for the evaluation of cerebral ischemic lesions after carotid intervention. ${ }^{3,14)}$ Diffusion-weighted imaging detected $98 \%$ of ischemic lesions, FLAIR imaging detected $91 \%$, and early $\mathrm{T}_{2}$-weighted or proton densityweighted imaging detected only $71 \%$ and $80 \%$, respectively. ${ }^{26)}$ Only 29\% of ischemic lesions depicted by diffusion-weighted imaging were visible on $\mathrm{T}_{2^{-}}$ weighted MR imaging. Diffusion-weighted imaging has the advantages of low false negative findings, obvious discrimination between nonischemic brain tissue and new embolic event, and between acute and chronic cerebral ischemic lesions. ${ }^{15,16)}$ Therefore, diffusion-weighted imaging facilitates the determination of the type, site, and extent of cerebral ischemia at an early stage. ${ }^{28,31)}$

Diffusion-weighted imaging is highly sensitive for large ischemic lesions, but might not be for small lesions. Conventional diffusion-weighted imaging studies used 5-mm section thickness with 1-mm intersection gap. If a lesion is smaller than the section thickness and occupies only part of a voxel, the contrast relative to background tissue depends on both the signal intensity of the lesion and the proportion of the voxel occupied. Small, low-contrast lesions occupying only part of a voxel may go undetected. Therefore, false negative results could occur with small embolic infarctions. ${ }^{31)}$ The present thin-section diffusion-weighted imaging protocol used 3-mm section thickness with no intersection gap, so permitted better lesion discrimination and more precise stroke diagnosis, and improved the detection accuracy for small infarcts despite the intrinsic limitations of diffusion-weighted imaging methodology.

The present study evaluated the safety and efficacy of different neuroprotection devices used during CAS by using thin-section diffusion-weighted imaging to detect new distal cerebral ischemic lesions. Lower incidences of new embolic lesions were found in patients treated with proximal flow reverse protection devices, distal balloon protection with Naviballoon, and with the filter anti-embolic devices, as compared to single or double distal balloon protection using the PercuSurge GuardWire. However, these lower incidences did not correlate to maximum neuroprotection as the volumes of these ischemic lesions were quite different. Higher total lesion volume was found in patients treated using the Parodi Anti-embolic System and Naviballoon. Using the distal double balloon protection technique, a second balloon was introduced to occlude the external carotid artery. Theoretically, this will interrupt any potential embolic pathway through the anastomotic channels between the external and internal carotid arteries. We reported a lower incidence of ipsilateral and contralateral ischemia using double balloon protection as compared to single balloon protection. However, ipsilateral and contralateral lesion volumes per lesion were larger using double balloon protection $(62.8$ $\mathrm{mm}^{3}$ and $98.8 \mathrm{~mm}^{3}$ ) compared to single balloon protection $\left(56.9 \mathrm{~mm}^{3}\right.$ and $\left.84.7 \mathrm{~mm}^{3}\right)$, indicating that the introduction of a second balloon for external carotid artery protection carried the risk of plaque mobilization and subsequent release of new embolic debris before protection was achieved. This finding was supported by the higher number of contralateral lesions and larger total contralateral lesion volume per patient following treatment using double balloon protection.

The efficacy and limitations of these protection devices have been widely investigated. An ex vivo study reported that all protection devices caused histologically visible wall damage which commonly resulted in dislodged debris during deployment and retrieval of the devices. ${ }^{20)}$ A significantly reduced frequency of microembolic signals were detected by transcranial Doppler ultrasonography during CAS using distal balloon protection. ${ }^{1)}$ No differences were found in the rates of clinical events between filter and distal occlusive devices. ${ }^{34)}$

Our experience with filter devices is limited due to the small number of patients. Further, commercially available filter devices in Japan have lower flexibility and larger crossing profile with rough coating, making navigation of balloon catheters and stents more difficult. However, the lower incidence of clinical events and lower lesion number and total lesion volume per patient do illustrate the efficacy of these new filter anti-embolic devices. Microembolic lesions detectable with diffusion-weighted imaging appeared in $26 \%$ of patients treated with a distal filter device versus $36 \%$ of patients treated with unprotected CAS. ${ }^{8)}$ A series of 162 CAS procedures involved distal ischemic events in $17.3 \%$ of patients, and the number of lesions per patient was $2.07,{ }^{23)}$ compared to 2.8 in our study. However, all filtration devices have programmed pores to permit antegrade blood flow, which may allow particles smaller than the pore size to pass through the filter, and these 
small microemboli may not be visible using diffusion-weighted imaging. ${ }^{21)}$

In our study, diffusion-weighted imaging was performed within 4 days of the procedures. Previous experimental studies showed that diffusion-weighted imaging can detect cerebral ischemic lesions as early as minutes to 3 hours ${ }^{17,24)}$ and within 2 to 6 hours after the onset of symptoms in humans. ${ }^{16,29,30)}$ Our study detected new contralateral ischemic lesions in $20.4 \%$ of our patients. We may assume that all intraarterial manipulation carries a certain risk for embolism and subsequent ischemic events. ${ }^{30)}$ Cerebral embolic events may occur during diagnostic angiography performed at early CAS caused by thromboembolism or air embolism introduced by injection of contrast medium or catheter flushing. ${ }^{23)}$ The apparently high incidence of contralateral lesions matched previous studies using diagnostic angiography. New ischemic lesions occurred in $29 \%$ of 59 patients after diagnostic angiography, and the frequency of lesions was correlated to the amount of contrast medium, timing of the procedure, number of vessels difficult to probe, and use of more than one catheter. ${ }^{5)}$ The upper boundary of $9 \%$ abnormalities associated with angiography is supported by diffusion-weighted imaging of asymptomatic patients, ${ }^{6)}$ and $69.2 \%$ of lesions in our study were located in the vascular territory of the treated carotid artery, suggesting that microembolism may occur at any time during CAS.

Ex vivo evaluation of the risk of embolization at various stages of carotid bifurcation balloon angioplasty showed that angioplasty generates embolic particles after each stage of the procedure, with the maximum particle size increasing from $220 \mu \mathrm{m}$ during wire/catheter passage to $1100 \mu \mathrm{m}$ after angioplasty. ${ }^{7}$ A clinical study identified increased microembolic signal counts during unprotected CAS using multichannel transcranial Doppler ultrasonography during stent deployment, predilation, and postdilation, with the highest count observed during stent deployment. Stent deployment is generally believed to be associated with a lower incidence of embolic signals due to the scaffolding effect, which may trap the atherosclerotic debris against the carotid artery wall. In contrast, the present study found that a distal balloon protection system significantly reduced the frequency of microembolic signals during CAS, particularly during these three phases. ${ }^{1)}$

The present outcomes after protected CAS compared favorably with the upper boundary of distal cerebral ischemic lesions associated with surgery, such as a $34 \%$ incidence of embolic lesions after carotid endarterectomy, ${ }^{18)}$ although several other studies showed lower incidences of less than $10 \%$ using conventional repair. ${ }^{4,10)}$ New lesions were found on the side of stent placement in $15.3 \%$ of 72 patients who underwent CAS without the use of protection devices, but no new contralateral ischemic lesions. ${ }^{27)}$ We cannot compare those results with our study, as the previous study used conventional MR imaging with a section thickness of $6 \mathrm{~mm}$. The frequency and volume of new lesions detected may be different with the thin-section technique used in our study.

The present study found that high lesion volume and high number of new distal cerebral ischemic lesions detected by diffusion-weighted imaging are associated with neurological deficits after CAS. The lower incidences of distal ischemia using proximal flow reverse protection devices and the use of distal balloon protection with the Naviballoon is limited by the large lesion volumes of distal ischemia in these patients. The introduction of a second balloon for external carotid artery protection decreases the incidence of ipsilateral and contralateral new ischemic lesions, but increases the volume of contralateral ischemic lesions. We believe that the ideal protection device must offer lower incidence as well as smaller lesion volume and fewer newly occurring distal ischemic lesions. Such a device is currently not available, at least not in our institution.

\section{Acknowledgment}

We have no personal or institutional financial interest in the supplies used in this article.

We thank Mr. Mahmoud Al-Sayed for his help in statistical analysis and Ms. Yamamoto and Dr. Ashraf Ragab (Faculty of Medicine, Zagazig University, Zagazig, Egypt) for their help in editing.

\section{References}

1) Al-Mubarak N, Roubin GS, Vitek JJ, Iyer SS, New G, Leo MB: Effect of distal-balloon protection system on microembolization during carotid stenting. Circulation 104: 1999-2002, 2001

2) Asakura F, Kawaguchi K, Sakaida H, Toma N, Matsushima S, Kuraishi K, Tanemura H, Miura Y, Maeda M, Taki W: Diffusion-weighted MR imaging in carotid angioplasty and stenting with protection by the reversed carotid arterial flow. AJNR Am J Neuroradiol 27: 753-758, 2006

3) Baird AE, Benfield A, Schlaug G, Siewert B, Lovblad KO, Adelman RR, Warach S: Enlargement of human cerebral ischemic lesion volumes measured by diffusion-weighted magnetic resonance imaging. Ann Neurol 41: 581-589, 1997

4) Barth A, Remonda L, Lovblad KO, Schroth G, Seiler 
RW: Silent cerebral ischemia detected by diffusionweighted MRI after carotid endarterectomy. Stroke 31: 1824-1828, 2000

5) Bendszus M, Koltzenburg M, Burger R, WarmuthMetz M, Hofmann E, Solymosi L: Silent embolism in diagnostic cerebral angiography and neurointerventional procedures: a prospective study. Lancet 354 : 1594-1597, 1999

6) Britt PM, Heiserman JE, Snider RM, Shill HA, Bird CR, Wallace RC: Incidence of postangiographic abnormalities revealed by diffusion-weighted MR imaging. AJNR Am J Neuroradiol 21: 55-59, 2000

7) Coggia M, Goeau-Brissonniere O, Duval JL, Leschi JP, Letort M, Nagel MD: Embolic risk of the different stages of carotid bifurcation angioplasty: an experimental study. J Vasc Surg 31: 550-557, 2000

8) Cosottini M, Michelassi MC, Puglioli M, Lazzarotti G, Michelassi MC, Del Corona A, Bartolozzi C, Murri L: Silent cerebral ischemia detected with diffusionweighted imaging in patients treated with protected and unprotected carotid artery stenting. Stroke 36: 2389-2399, 2005

9) Cremonesi A, Manetti R, Setaci C, Castriota F: Protected carotid stenting: clinical advantages and complications of embolic protection devices in 442 consecutive patients. Stroke 34: 1936-1941, 2003

10) Feiwell RJ, Besmertis L, Sarkar R, Saloner DA, Rapp JH: Detection of clinically silent infarcts after carotid endarterectomy by use of diffusion-weighted imaging. AJNR Am J Neuroradiol 22: 646-649, 2001

11) Henry M, Amor M, Henry I, Klonaris C, Chati Z, Massoni I, Kowanotor S, Luizy F, Hugel M: Carotid stenting with cerebral protection: first clinical experience using the PercuSurge GuardWire system. J Endovasc Surg 6: 321-331, 1999

12) Hill MD, Morrish W, Soulez G, Nevelsteen A, Maleux G, Rogers C, Hauptmann KE, Bonafé A, Beyar R, Gruberg L, Schofer J; MAVErlC International Investigators: Multicenter evaluation of a self-expanding stent system with distal protection in the treatment of carotid stenosis. AJNR Am J Neuroradiol 27: 759-765, 2006

13) Jaeger HJ, Mathias KD, Hauth E, Drescher R, Gissler HM, Hennigs S, Christmann A: Cerebral ischemia detected with diffusion-weighted MR imaging after stent implantation in the carotid stenting. AJNR Am J Neuroradiol 23: 200-207, 2002

14) Lovblad KO, Pluschke W, Remonda L, Gruber-Wiest D, Do DD, Barth A, Kriemeyer HW, Bassetti C, Mattle HP, Schroth G: Diffusion-weighted MRI for monitoring neurovascular interventions. Neuroradiology 42: 134-138, 2000

15) Lutsep HL, Albers GW, DeCrespigny A, Kamat GN, Marks MP, Mosely ME: Clinical utility of diffusionweighted imaging in the assessment of ischemic stroke. Ann Neurol 41: 574-580, 1997

16) Marks MP, de Crespigny A, Lentz D, Enznman DR, Albers GW, Moseley MF: Acute and chronic stroke: navigated spin-echo diffusion-weighted MR imaging.
Radiology 199: 403-408, 1996

17) Moseley ME, Kucharczyk J, Mintorovitch J, Cohen Y, Kurhanewicz J, Derugin N, Asgari H, Norman D: Diffusion-weighted MR imaging of acute stroke: correlation with $\mathrm{T} 2$-weighted and magnetic susceptibility-enhanced MR imaging in cats. AJNR Am J Neuroradiol 11: 423-429, 1990

18) Muller $M$, Reiche W, Langenscheidt P, Hassfeld J, Hagen T: Ischemia after carotid endarterectomy: comparison between transcranial Doppler sonography and diffusion-weighted MR imaging. AJNR Am J Neuroradiol 21: 47-54, 2000

19) Muller-Hulsbeck S, Jahnke T, Liess C, Glass C, Grimm J, Heller M: Comparison of various cerebral protection devices used for carotid artery stent placement: an in vitro experiment. J Vasc Interv Radiol 14: 613-620, 2003

20) Muller-Hulsbeck S, Stolzman P, Liess C, Hedderich J, Paulsen F, Jahnke T, Heller M: Vessel wall damage caused by cerebral protection devices: ex vivo evaluation in porcine carotid arteries. Radiology 235: 454-460, 2005

21) Ohki T, Parodi J, Veith FJ, Bates M, Bade M, Chang D, Mehta M, Rabin J, Goldstein K, Harvey J, Lipsitz E: Efficacy of a proximal occlusion catheter with reversal of flow in the prevention of embolic events during carotid artery stenting: an experimental analysis. J Vasc Surg 33: 504-509, 2001

22) Ohki T, Roubin GS, Veith FJ, Iyer SS, Brady E: Efficacy of a filter device in the prevention of embolic events during carotid angioplasty and stenting: an ex vivo study. J Vasc Surg 30: 1034-1044, 1999

23) Pinero P, González A, Mayol A, Martînez E, González-Marcos JR, Boza F, Cayuela A, Gil-Peralta A: Silent ischemia after neuroprotected percutaneous carotid stenting: A diffusion-weighted MRI study. AJNR Am J Neuroradiol 27: 1338-1345, 2006

24) Reith W, Hasegawa Y, Latour LL, Dardzinski BJ, Sotak $\mathrm{CH}$, Fisher M: Multislice diffusion mapping for 3-D evolution of cerebral ischemia in rat stroke model. Neurology 45: 172-177, 1995

25) Sztriha LK, Vörös E, Sas K, Szentgyörgyi R, Pócsik A, Barzó P, Szikra P, Makai A, Szólics A, Elek P, Rudas L, Vécsei L: Favorable early outcome of carotid artery stenting without protection devices. Stroke 35: 2862-2866, 2004

26) van Everdingen KJ, van der Grond J, Kappelle LJ, Ramos LM, Mali WP: Diffusion-weighted magnetic resonance imaging in acute stroke. Stroke 29: 1783-1790, 1998

27) van Heesewijk HP, Vos JA, Louwerse ES, Van Den Berg JC, Overtoom TT, Ernst SM, Mauser HW, Moll FL, Ackerstaff RG; Carotid PTA and Stenting Collaborative Research Group: New brain lesions at MR imaging after carotid angioplasty and stent placement. Radiology 224: 361-365, 2002

28) Vermeer SE, Prins ND, den Heijer T, Hofman A, Koudstaal PJ, Breteler MM: Silent brain infarcts and the risk of dementia and cognitive decline. $N$ Engl J 
Med 348: 1215-1222, 2003

29) Warach S, Dashe JF, Eldelman RR: Clinical outcome in ischemic stroke predicted by early diffusionweighted and perfusion magnetic resonance imaging: a preliminary analysis. J Cereb Blood Flow Metab 16: 53-59, 1996

30) Warach S, Gaa J, Siewert B, Wielopolski P, Edelman RR: Acute human stroke studied by whole brain echo planar diffusion-weighted magnetic resonance imaging. Ann Neurol 37: 231-241, 1995

31) Wolf O, Heider P, Heinz M, Poppert H, SchmidtThieme T, Sander D, Gräfin von Einsiedel H, Brandl R: Frequency, clinical significance and course of cerebral ischemic events after carotid endarterectomy evaluated by serial diffusion weighted imaging. Eur J Vasc Endovasc Surg 27: 167-171, 2004

32) Yadav JS, Roubin GS, Iyer S, Vitek J, King P, Jordan WD, Fisher WS: Elective stenting of the extracranial carotid arteries. Circulation 95: 376-381, 1997

33) Yadav JS, Wholey MH, Kuntz RE, Fayad P, Katzen BT, Mishkel GJ, Bajwa TK, Whitlow P, Strickman NE, Jaff MR, Popma JJ, Snead DB, Cutlip DE, Firth BG, Ouriel K; Stenting and Angioplasty with Protection in Patients at High Risk for Endarterectomy Investigators: Protected carotid-artery stenting versus endarterectomy in high-risk patients. N Engl J Med 351: 1493-1501, 2004

34) Zahn R, Ischinger T, Mark B, Gass S, Zeymer U, Schmalz W, Haerten K, Hauptmann KE, von Leitner ER, Kasper W, Tebbe U, Senges J; Arbeitsgemeinschaft Leitende Kardiologische Krankenhausärzte (ALKK): Embolic protection devices for carotid artery stenting: is there a difference between filter and distal occlusive devices. J Am Coll Cardiol 45: 1769-1774, 2005

35) Zahn R, Mark B, Niedermaier N, Zeymer U, Limbourg $\mathrm{P}$, Ischinger $\mathrm{T}$, Haerten $\mathrm{K}$, Hauptmann $\mathrm{KE}$, Leitner ER, Kasper W, Tebbe U, Senges J; Arbeitsgemeinschaft Leitende Kardiologische Krankenhausärzte (ALKK): Embolic protection devices for carotid artery stenting: better results than stenting without protection? Eur Heart J 25: 1550-1558, 2004
Address reprint requests to: Waro Taki, M.D., Department of Neurosurgery, Mie University School of Medicine, 2-174 Edobashi, Tsu, Mie 514-8507, Japan. e-mail:nousinke@clin.medic.mie-u.ac.jp

\section{Commentary}

The authors are congratulated on a rigorous prospective assessment of ischemic burden after carotid angioplasty and stenting (CAS) using diffusion-weighted magnetic resonance imaging (DWI) in the setting of several anti-embolic protection devices. They have confirmed that the procedure is accompanied by low risk of clinical complications in carefully selected cases and with experienced teams, approximately 3\% in this series. But the rate of clinically silent ischemia is very high, despite a variety of technical adjuncts, ranging from $33 \%$ to $48 \%$ with the various devices, all higher than the highest range of reported DWI lesions after carotid endarterectomy.

Risk factors for development of new ischemic lesions were highly significant in univariate analyses, including symptomatic disease, more severe stenoses, contralateral carotid occlusion, and medical co-morbidities. Comparative rates of DWI lesions and their respective volumes were carefully analyzed by the authors, and mechanistic explanations were suggested. We would caution that many such differences did not achieve statistical significance, given the small numbers of cases in each stratum, and it is not clear that all differences were in fact due to the respective device (rather than the risk factors identified above), since the device-related risks were not adjusted for disease risk factors in multivariate analysis.

Issam A. AWAD, M.D., M.Sc., F.A.C.S., M.A. (Hon.) Professor of Neurological Surgery NorthShore University HealthSystem Evanston, Illinois, U.S.A. 